\title{
A COMUNICAÇÃO PROFISSIONAL DE SAÚDE X CLIENTE DIANTE DAS NOVAS TECNOLOGIAS
}

HEALTH PROFESSIONAL COMMUNICATION $X$ CUIENT FACING NEW TECHNOLOGIES.

LA COMUNICACIÓN PROFESIONAL DE SALUD $X$ CLENTE DELANTE DE LAS NUEVAS TECNOLOCÍAS

Carmen Luci R. Lopes ${ }^{1}$

Maria Alves Barbosa ${ }^{1}$

Maria Eunice M. Teixeira ${ }^{1}$

Renata Benevides Coelho ${ }^{1}$

RESUMO: Estudo descritivo exploratório com abordagem quanti-qualitativa realizado em unidades das redes pública e privada localizadas em Goiânia-Go., nos meses de agosto e setembro de 1997 com objetivos de averiguar o entendimento dos clientes a respeito da comunicação dos profissionais que executam os exames de alta tecnologia $\theta$ detectar junto ao cliente a existência de orientação sobre o exame a ser realizado e o que sentem durante a realização destes. A população constitui-se de clientes de ambos os sexos que se submeteram a exames diagnósticos de alta tecnologia. Os dados foram coletados pelas pesquisadoras e auxiliares de pesquisa, mediante entrevista semi-estruturada entre os clientes sujeitos do estudo. Através dos resultados, concluímos que a maioria dos clientes não recebem orientação, deixaram de pedir informações sobre o exame realizado por vários motivos, inclusive receio do desconhecido. A comunicaçāo foi restrita. Medo da dor, do resultado, desconforto foram também relatados.

UNITERMOS: Comunicação - Clientes - Novas tecnologias.

\begin{abstract}
Descriptive exploratory study with quanti-qualitative apprroach accomplished at public and private net units in Goiânia - GO from August to September, 1997 aiming at observing clients understanding of communication of the professionals who perform high technology exams and identifying whether any orientation provided to clients about the exams that are to be performed and their impressions during their performance. The population is of clients of both sexes who have undergone high technology diagnosis examinations. The data have been collected by the authors and research aids through semistructured interviews among the study subject clients. By the results, we have concluded that the majority of the clienta does not receive any orientation, lacked information about the exam that is to be performed for severl reasons, including fear of the unknown. Communication was restrict. Fear of pain, of the result, diiscomfort have also been reported.
\end{abstract}

KEYWORDS: Communication - Clients - New technologies.

${ }^{1}$ Enfermeiras docentes da Faculdade de Enfermagem/UFG.

R. Bras. Enferm. Brasilia, v. 51, n. 1, p. 53-62, jan./mar., 1998 
RESUMEN: Estudio descriptivo exploratorio con abordaje cuanti-cualitativa realizado en unidades de las mallas públicas y privada localizadas en Goiânia-Go., en los meses de agosto y septiembre de 1997 con objetivos de averiguar el entendimiento de los clientes a respecto de la comunicación de los profesionales que ejecutan los exámenes de alta tecnología y detectar junto al cliente la existencia de orientación sobre el exámen a ser realizado y lo que sienten durante la realización de éstos. La población se constituye de clientes de ambos sexos que se sometieron a exámenes diagnósticos de alta tecnología. Los datos fueron recopilados por las investigadoras y auxiliares de investigación, mediante entrevista semi estruturada entre los clientes sujetos del estudio. Por medio de los resultados, concluimos que la mayoría de los clientes no reciben orientación, dejaron de pedir informaciones sobre el exámen realizado por varios motivos, inclusive temor de lo desconocido. La comunicación fué restricta. Miedo de dolor, del resultado, desconforto fueron también relatados.

UNITÉRMINOS: Comunicación - Clientes - Nuevas tecnologías.

\section{INTRODUÇÃO}

Desde os primórdios da civilização, os aspectos da comunicação e/ou relacionamento constituem objeto de preocupação e estudo, inclusive na área de saúde.

Com a Revolução Industrial surge também o desenvolvimento de Novas Tecnologias em praticamente todas as áreas do conhecimento.

$\mathrm{Na}$ modernidade, guiada pela ideologia do progresso, tudo o que era considerado "primitivo" no viver humano, foi substituído pela hiper-racionalidade. A felicidade passou a estar vinculada ao êxito do projeto progressista. A sociedade moderna impôs-se como laboriosa e energética, hierática, homogênea e linear, pois só conhecia a meta do progresso e este novo tempo reclama por novas posturas cientificas, ou melhor, por uma nova atitude intelectual (Rezende, 1993).

Noronha (1985) enfatiza que os tempos atuais caracterizam-se por profundas mudanças, as quais sofrem uma aceleração constante e quase que de forma vertiginosa no que diz respeito aos avanços tecnológicos.

É importante ressaltar que estes avanços também ocorreram na área de saúde. Esta afirmativa é condizente com as informaçőes de Boemer (1986), quando afirma que uma invasão da técnica com todo tipo de maquinário vem sendo criado pelo homem a partir de seu conhecimento. Essa tecnologia moderna, criada pelo homem a serviço do homem, tem contribuido em larga escala para solução de problemas antes insolúveis e podem reverter em melhores condiçöes para o paciente.

Revendo Rezende (1987), verificamos que a descoberta dos raios X, no final do século XIX, e sua aplicaçăo com fins diagnósticos no início deste século constituíram um marco importante na história da medicina. O sucessb do 
emprego dos raios $\mathrm{X}$ levou os profissionais à busca de outros métodos diagnósticos por imagens, sendo presenciado nesta geração o aparecimento da ultrassonografia, da tomografia computadorizada e da ressonância nuclear magnética, dentre outros.

As técnicas de obtenção de imagens do corpo humano assumiram modernamente um extraordinário papel na avaliação das enfermidades do ser humano ou do diagnóstico, seguimento e tratamento das anormalidades e enfermidades em geral (Flores, 1992).

De acordo com Magalhães (1992), a evolução tecnológica, com o uso de computadores e o telecomando, vem dando ao diagnóstico radiológico importância fundamental por permitir a visão direta da estrutura dos diferentes órgãos do corpo humano.

São relevantes as afirmações de Noronha (1985) de que todos os progressos tecnológicos foram possíveis através do homem e para ele, mas em virtude deles o homem também passou por profundas modificações em suas condutas, sua maneira de pensar e até mesmo suas crenças, deixando por vezes de "enxergar" o ser humano como um todo, com aspectos humanos, éticos e religiosos, dando mais importância à máquina do que ao próprio homem.

Boemer (1986) chama a atenção para o grande arsenal tecnológico que há nos hospitais, nos consultórios médicos, nos laboratórios e serviços de raios $\mathrm{X}$, e afirma que a grande incoerência, entretanto, é que essa tecnologia, desenvolvida pelo homem para o homem acabou por afastar esses dois homens, afastamento esse inconcebível pela inalienabilidade intrínseca de ambos. A autora considera que esse afastamento gerou algo mais grave - a máquina passou a substituir o homem nas funções cabiveis a esse homem.

Germano (1993) alerta que, por um lado, o rápido crescimento de técnicas cirúrgicas e farmacológicas, aliadas a todo um aparato tecnológico aludido, concedeu aos profissionais uma possibilidade de maior intervenção no prolongamento da vida e que, por outro, não ocorreu com a mesma intensidade uma preocupação com os aspectos psicológicos que envolvem os pacientes admitidos nesses serviços. Ressaltamos a importåncia do avanço tecnológico, entretanto, enfatizamos a necessidade de que os profissionais desta área saibam lidar não só com os novos inventos, mas também que tenham como base do seu trabalho o uso adequado das técnicas da comunicação interpessoal.

$\mathrm{Na}$ visão de Silva (1996), somente pela comunicação efetiva é que o profissional poderá ajudar o paciente a conceituar seus problemas, enfrentá-los, visualizar sua participação na experiência e alternativas de solução dos mesmos, além de auxiliá-lo a encontrar novos padröes de comportamento.

Feldmann, apud Germano (1993), informa que

"O avanço tecnológico desencadeou um processo de quantificação $e$ abstratificação que extrapolou a esfera do político, da produção e da economia, invadindo as inter-relações humanas". 
$\mathrm{Na}$ equipe de saúde esse feno̊meno também está presente, pois o paciente deixa de ser uma pessoa para ser um caso interessante. O paciente individualizado, com seus problemas, temores e necessidades não é sempre levado em conta.

As alteraçőes fisiológicas são facilmente detectadas, o que nem sempre ocorre com as de ordem psicossocial, já que poucas săo as informaçőes sobre métodos de atendimento comprovadamente eficientes (Ciosak,1982).

Amorim, apud Germano (1993), refere que muitas vezes a presença do indivíduo como ser humano, é ignorada pelos profissionais que o assistem, e que a sensação de menosprezo e de falta de respeito à dignidade é angustiante. $E$ afirma ainda que a angústia, além de agravar a sintomatologia, algumas vezes chega a impedir a realização de certos exames e tratamentos.

Catarino e cols.(1996) afirmam que, atualmente, no campo da saúde se acentua a dependência de novas e dispendiosas tecnologias. No entanto, precisa-se de um sistema que, mais do que pela excelência de instalações e novos equipamentos, seja resultante da interaçăo entre a humanizaçăo e a excelência técnica. Afirmam ainda que a qualidade global de um sistema de saúde deve ser resultante da complementaridade entre a excelência técnica e um comportamento afetivo e humanizado por todos os profissionais.

\section{Segundo Barbosa (1990),}

"numa época em que a vida se torna cada vez mais competitiva, a luta pela sobrevivência, pelo Status e pelo poder, faz com que o "outro e o tempo" sejam quase sempre vistos como adversários; as relações interpessoais ficam prejudicadas; não há tempo para aprofundá-las.

A impressão que se tem é que existe uma carência pairada no ar". A autora afirma ainda que as relaçőes profissionais entre os membros da equipe de saúde e desta com a clientela é exemplo notório.

Defensoras que somos da comunicação efetiva equipe de saúde/paciente, observamos na nossa trajetória como docentes nos campos de prática que a maioria dos clientes, quando văo submeter-se a algum tipo de exame, desconhecem o processo de realização do mesmo e até para que serve. Percebemos também a necessidade de orientações nestas situações no sentido de esclarecê-los a fim de diminuir a apreensão, o que poderá resultar em maior colaboraçăo. Sabemos que na realidade isto năo é fácil de realizar. É mais fácil e produz menos tensão na equipe de saúde ver o enfermo como paciente e não como ser humano.

Ponderando sobre todos estes fatores, despertou em nós o interesse em realizar este estudo visando investigar o processo de comunicaçăo entre os clientes submetidos a procedimentos de alta tecnologia e a equipe de saúde. 


\section{OBJETIVOS}

- Averiguar o entendimento dos clientes a respeito da comunicaçăo efetivada pelos profissionais que executam os exames de alta tecnologia;

- Detectar junto aos clientes a existência de orientação sobre o exame a ser realizado e o que sentem durante a realizaçăo destes.

\section{METODOLOGIA}

Optamos por um estudo descritivo exploratório com abordagem quantiqualitativa. Foi realizado em unidades das redes pública e privada localizadas em Goiânia-GO, no período de agosto e setembro de 1997.

A populaçăo constitui-se de clientes que se submeteram a exames diagnósticos de alta tecnologia, entre eles a endoscopia, mamografia, ultrassonografia mamária e transvaginal, tomografia computadorizada, ecocardiograma, densitometria óssea, $\mathrm{RX}$ de esôfago com contraste e cateterismo cardíaco.

A amostra foi constituída de clientes que se dispuseram a participar do estudo, totalizando 30 pessoas.

Os dados foram coletados mediante entrevista individual realizada pelas pesquisadoras e auxiliares da pesquisa entre os clientes sujeitos do estudo.

Procuramos destacar os sujeitos envolvidos $\theta$ o tipo de interaçőes ocorridas, ressaltando-se as emoçőes dos sujeitos, considerando o tipo de exame.

Os resultados foram apresentados em tabelas com frequeência e cálculo de percentagem simples e análise quanti-qualitativa, o que permitiu uma melhor compreensăo dos dados obtidos.

\section{ANÁLISE E DISCUSSÃO DOS RESULTADOS}

TABELA 1 - DISTRIBUIÇÃO DOS CLIENTES ENTREVISTADOS SEGUNDO A FAIXA ETÁRIA E O SEXO- 1997.

\begin{tabular}{|c|c|c|c|c|c|c|}
\hline \multirow{2}{*}{ FAIXA ETÁRIA } & \multicolumn{2}{|c|}{ MASCULINO } & \multicolumn{2}{|c|}{ FEMININO } & \multicolumn{2}{|c|}{ TOTAL } \\
\hline & FI & $\%$ & $\mathrm{FI}$ & $\%$ & $\mathrm{FI}$ & $\%$ \\
\hline $10-30$ anos & 01 & 14,3 & 04 & 17,4 & 05 & 16,6 \\
\hline $30-50$ anos & 01 & 14,3 & 10 & 43,5 & 11 & 36,7 \\
\hline $50-80$ anos & 05 & 71,4 & 09 & 39,1 & 14 & 46,7 \\
\hline TOTAL & 07 & 100,0 & 23 & 100,0 & 30 & 100,0 \\
\hline
\end{tabular}


No que se réfere às características dos pacientes submetidos a exames diagnósticos de alta tecnologia, observamos na Tabela 1 que há predominância do sexo feminino e que a faixa etária variou entre 10 a 80 anos, sendo que houve uma maior freqüência dos 50 a 80 anos.

TABELA 2 - DISTRIBUIÇÃO DOS CLIENTES SEGUNDO O GRAU DE ESCOLARIDADE - 1997.

\begin{tabular}{l|c|c}
\multicolumn{1}{c|}{ ESCOLARIDADE } & $\mathrm{Fi}$ & $\%$ \\
\hline analfabeto & 5 & 16,7 \\
\hline $1^{\circ} \mathrm{Grau}$ completo & 2 & 6,7 \\
\hline $1^{\circ} \mathrm{Grau}$ incompleto & 10 & 33,4 \\
\hline $2^{\circ} \mathrm{Grau}$ & 4 & 13,3 \\
\hline nivel superior & 7 & 23,3 \\
\hline alfabetizado & 1 & 3,3 \\
\hline não informou TOTAL & 1 & 3,3 \\
\hline \multicolumn{1}{c|}{} & 30 & $\mathbf{1 0 0 , 0}$ \\
\hline
\end{tabular}

Observa-se na Tabela II que a maioria possui o $1^{\circ} \mathrm{Grau}$ incompleto $(33,4 \%)$, seguido do nível superior $(23,3 \%)$. Os não alfabetizados foram em número de 05 , correspondendo a $16,7 \%$. Observamos nas nossas entrevistas que, quanto menor o grau de escolaridade, o indivíduo se torna menos exigente, se satisfaz com informaçø̃es incompletas e também indaga menos.

TABELA 2 - DISTRIBUIÇÃO DOS CLIENTES QUANTO A ORIENTAÇÃO RECEBIDA SOBRE OS EXAMES - GOIÅNIA - 1997

\begin{tabular}{cc|c|c}
\hline \multicolumn{1}{c|}{ ORIENTAÇÃO } & FI & $\%$ \\
\hline sim & 17 & 56,6 \\
\hline não & 13 & 43,4 \\
\hline \multicolumn{2}{c|}{ TOTAL } & 30 & 100,0 \\
\hline
\end{tabular}

A Tabela 3 revela que $56,65 \%$ dos clientes afirmaram terem recebido informaçőes acerca dos exames a que foram submetidos e $43,4 \%$ relataram não ter recebido orientação alguma.

A nosso ver, para orientarmos o cliente sobre determinados exames, necessitamos estar preparados a fim de não cometermos exageros. A honestidade e o respeito săo quesitos importantes, pois, dependendo do estado de ansiedade em que ele se encontra, o conhecimento pode vir a ser prejudicial $\theta$ até mesmo desastroso.

A falta de conhecimento sobre os procedimentos contribui para que a maioria dos profissionais tenham dificuldade em se comunicar.

Rezende (1993), afirma que este novo tempo reclama por novas posturas cientificas, ou melhor, por uma atitude intelectual. É a pós-modernidade marcada pelo advento das inovaçס̋es técnico-cientificas que responde a esses anseios. 
Os clientes que relataram terem sido orientados afirmaram ter sido apenas pelo seu médico e que esta orientaçăo năo foi satisfatória, tendo continuado assim inseguros quanto ao exame.

TABELA 4 - DISTRIBUIÇÃO DA OPINIĀO DOS CLIENTES REFERENTES A VIVENCIA DOS SINTOMAS EMOCIONAIS DURANTE A REALIZZAÇÃO DOS EXAMES AGOSTO/SETEMBRO,1997.

\begin{tabular}{|c|c|c|}
\hline EMOÇOÖES/SENTIMENTOS/REAÇÃO & $\mathrm{Fi}$ & $\%$ \\
\hline tranquilidade & 06 & 15,4 \\
\hline medo & 15 & 38,5 \\
\hline "stress" & 07 & 13,9 \\
\hline angústia & 01 & 2,5 \\
\hline desconforto & 02 & 5,1 \\
\hline indiferença & 03 & 7,7 \\
\hline outros & 05 & 12,8 \\
\hline TOTAL & 39 & 100,0 \\
\hline
\end{tabular}

OBS: questão com múltiplas escolhas.

A Tabela 4 revela que o maior número de respostas apontam para a reação de medo, $38,5 \%$. Os clientes relataram que o medo aumenta muito frente ao desconhecido.

Em relaçăo às emoçőes dos clientes durante os procedimentos, foram relatados:

"É um exame constrangedor, pois fica muito exposta."

No nosso entendimento, estes exames se tornam desagradáveis e constrangedores pelo fato de que a maioria dos funcionários, durante açóes que já se tornaram rotineiras, não observa a ansiedade gerada pela intrusão no espaço pessoal do cliente.

"Medo da dor, do resultado."

"Não sabia como era o exame."

Sabemos que a dor e o medo são os mais primitivos sofrimentos do homem, mas, à medida que ele adquire conhecimentos, essas sensaçőes podem ser amenizadas. Neste estudo observamos que, quando os pacientes eram orientados e não havia omissão de informaçőes, eles se sentiam mais seguros diante das experiências novas que iriam vivenciar.

Outros relataram ainda vergonha, desespero, angústia e taquicardia.

Segundo Carvalho (1985), a maioria dos distúrbios emocionais, da área afetiva e da emoçăo, em geral, surgem em consequência de falhas de comunicaçăo, de segurança e auto-estima.

Do nosso ponto de vista, os elementos da equipe de saúde que desenvolvem estas tecnologias devem estar atentos a tais alteraçōes, a fim de dar maior assistência aos clientes. Concordamos com Teixeira (1991) quando defende que a comunicação deve ser adequada, pois além de minimizar a ansiedade 
amplia a capacidade do cliente em aproveitar as informaçōes que the são transmitidas, estabelecendo-se assim um vínculo altamente proveitoso e satisfatório para ambos.

TABELA 5 - SUGESTÖES PARA MELHORAR O ATENDIMENTO REFERIDO PELOS PACIENTES NA REALIZAÇÅO DE EXAMES, DIAGNÓSTICOS DE ALTA TECNOLOGIA - GOIÂNIA, AGOSTO/SETEMBRO/1997.

\begin{tabular}{l|c|c}
\hline \multicolumn{1}{c|}{ SUGESTÕES DADAS } & FI & F\% \\
\hline $\begin{array}{l}\text { - Deveria haver melhor comunicação, explicar melhor aos clientes a } \\
\text { respeito dos exames. }\end{array}$ & 14 & 46,6 \\
\hline $\begin{array}{l}\text { - Que os profissionais que realizam os exames sejam mais } \\
\text { delicados com os clientes. }\end{array}$ & 1 & 3,3 \\
\hline - Não tiveram sugestões a dar. & 9 & 30,0 \\
\hline - Não responderam. & 4 & 13,3 \\
\hline - Esclarecer melhor os clientes, antes, durante, e após os exames. & 2 & 6,6 \\
\hline TOTAL & 30 & 100,0 \\
\hline
\end{tabular}

$\mathrm{Na}$ Tabela 5 verificamos que $46,6 \%$ dos clientes responderam que deveria haver melhor comunicação, explicar melhor aos clientes a respeito dos exames, $30 \%$ não tiveram sugestões a dar e $6,6 \%$ reforçaram o esclarecimento antes, durante e após os exames.

Evidenciamos frente aos relatos dos clientes a importância da comunicaçăo e explicação mais eficaz sobre os variados exames, pois, além de promoverem maior grau de conhecimento, favorecem sentimentos de segurança e cooperaçăo.

Silva (1996) reforça que a comunicação adequada é aquela que tenta diminuir os conflitos, mal-entendidos e atingir os objetivos definidos para a solução de problemas detectados na interaçăo com os clientes. A autora refere que já ficou comprovado que os doentes reclamam entre si e reprovam o profissional que "não é franco", "não diz direito o que a gente tem", "não fala tudo o que está pensando", além do próprio mutismo apresentado por muitos profissionais".

\section{CONSIDERAÇÕES FINAIS}

Os resultados do estudo apontam para a importância da comunicação equipe de saúde/cliente no desenvolvimento de exames de alta tecnologia como tentativa de reduzir as tensões emocionais dos clientes.

As interpretaçס̃es destes resultados levou-nos às seguintes conclusões: 
Independente do sexo, faixa etária, condições sócio-econômicas, algumas preocupações, como medo, "stress", ansiedade, estavam presentes na maioria dos entrevistados e poderiam ter sido reduzidas se informações inerentes aos exames fossem prestadas e se eles recebessem melhor orientação por parte dos membros da equipe.

Apesar de relevantes, as orientações anteriores e posteriores aos exames não foram prestadas segundo o relato dos clientes entrevistados.

É importante, portanto, salientar que o avanço tecnológico na área da saúde é uma grande conquista mas seria melhor associar esta tecnologia à comunicaçäo com vistas a obter resultados mais satisfatórios em relação ao bem-estar dos clientes.

\section{REFERÊNCIAS BIBLIOGRÁFICAS}

1. BARBOSA, Maria Alves. A Fitoterapia como Prática de Saúde - O Caso do Hospital de Terapia Ayurvedica de Goiânia. Dissertação (Mestrado em Enfermagem)Rio de Janeiro: EEAN, UFRJ, 1990, 257 p.

2. BOEMER, Magaly R. A Morte e o Morrer. São Paulo: Cortez, 1986.

3. CARVALHO, Vilma Daclé, et. al. Assistência de enfermagem a pacientes com manifestaçōes de distúrbio emocional, internados em unidade médico-cirúrgica. - Rev. Paul. Enferm. São. Paulo: v.5. n.1. p.35-37. jan/março, 1985.

4. CATARINO,Jorge; CASSIANO, José; SILVA, Rui Costa. O Respeito como princípio moral básico e princípio de enfermagem. Rev. Nursing; ano $9 \mathrm{n}^{\circ}$ 99, abril, 961996.

5. CIOSAK, S.I. e cols.. Estudo Preliminar sobre a Influência da Orientaçāo Sistematizada ao paciente que será submetido ao Estudo Hemodinâmico. R. Bras. Enferm.; D. F, v. 35, p.17-38, 1982.

6. CUSTÓDIO, Ronaldo de Oliveira. Apreciação de Princípios Importantes da Endoscopia Digestiva Alta, R. Ass. Med. Brasil, v. 33, n. 5/6mai./jun.,1987.

7. FLORES, José Antônio. Diagnóstico por Imagens em pediatria. $R$. Médica, Santa Casa, P. Alegre, 4(7): p. 754-764, 1992.

8. GERMANO, Raimunda M. A Ética $e$ ensino de Ética na Enfermagem do Brasil. S. Paulo: Cortez, 1993. 
9. MAGALHÃES, A. E. de Almeida. A Moderna Radiologia, Rev. Méd., São Paulo, v. 71, p. 93-98, ago., 1992.

10. NORONHA, Dulce C. V. e cols. Implicações Éticas na Assistência de Enfermagem do Paciente Crítico, R. Bras. Enferm. Brasília, v. 38, n.3/4, jul./dez.,1985.

11. REZENDE, Ana Lúcia Magela de. Pós-Modernidade - $O$ vitalismo no "Chaos", Plural, n. 4, p.5-12, jan./jul., 1993.

12. REZENDE, J. M. de. Perspectiva da Medicina para o século XXI. - Ver. Goiana Med. v. 33, p. 79-88, 1987.

13. SILVA, Maria Júlia Paes. A Comunicaçāo Tem Remédio - A Comunicaçăo nas Relações Interpessoais em Saúde. São Paulo: Ed. Gente, 1996. 